\title{
Stephan Meder, Christoph-Eric Mecke (dir.), Reformforderungen zum Familienrecht international: Westeuropa und die USA (1830-1914)
}

Laila Scheuch

\section{OpenEdition}

Journals

Édition électronique

URL : http://journals.openedition.org/ifha/8664

DOI : $10.4000 /$ ifha. 8664

ISSN : 2198-8943

Éditeur

IFRA - Institut franco-allemand (sciences historiques et sociales)

Référence électronique

Laila Scheuch, «Stephan Meder, Christoph-Eric Mecke (dir.), Reformforderungen zum Familienrecht international: Westeuropa und die USA (1830-1914) », Revue de I'IFHA [En ligne], Date de recension, mis en ligne le 01 février 2017, consulté le 24 septembre 2020. URL : http://journals.openedition.org/ifha/ 8664 ; DOI : https://doi.org/10.4000/ifha.8664

Ce document a été généré automatiquement le 24 septembre 2020

(CIFHA 


\section{Stephan Meder, Christoph-Eric Mecke (dir.), Reformforderungen zum} Familienrecht international: Westeuropa und die USA (1830-1914)

Laila Scheuch

\section{RÉFÉRENCE}

Stephan Meder, Christoph Eric Mecke (dir.), Reformforderungen zum Familienrecht international: Westeuropa und die USA (1830-1914), Köln: Böhlau (Rechtsgeschichte und Geschlechterforschung, 17,1), 2015, 805 p., $120 €$ 
Ce recueil est consacré aux revendications des mouvements féministes relatives au droit privé et à la situation juridique des femmes pendant le «long " XIX ${ }^{\mathrm{e}}$ siècle dans les pays de l'Europe de l'Ouest et aux États-Unis. L'ouvrage clôture le projet de la Deutsche Forschungsgemeinschaft "Internationale Reformforderungen zum Familienrecht und Rechtskämpfe des Frauenweltbundes" (2007-2012) de l'université de Hanovre. Les 24 contributions, dont la plupart ont été écrites par de jeunes chercheurs de la faculté de droit de cette université, y compris des étudiants, sont organisées selon un principe "géopolitique" comportant des sections qui concernent la France, l'Angleterre, les États-Unis, la Scandinavie et une section finale qui

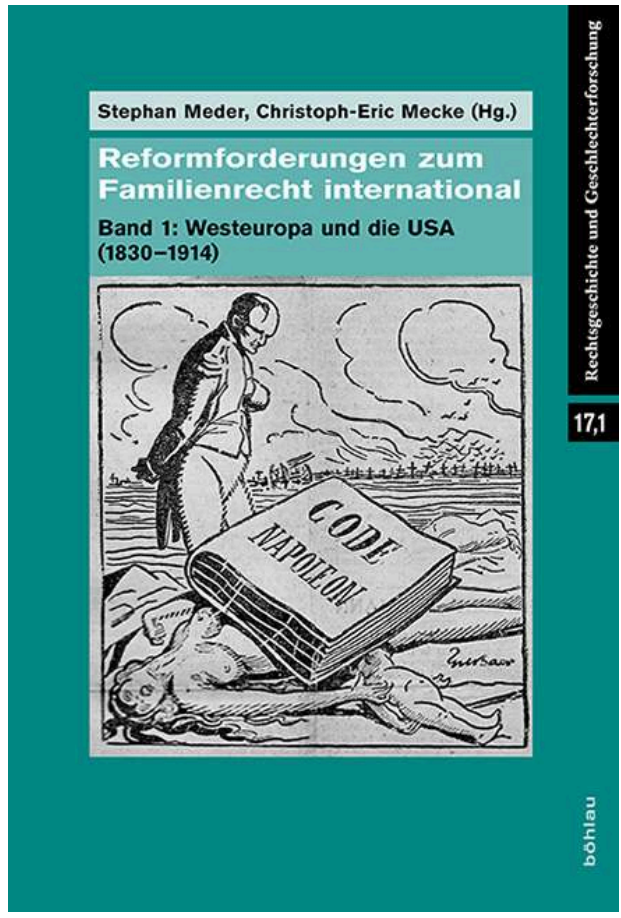
traite des organisations pour les droits des femmes à l'échelle internationale. Cinq articles établissent une comparaison avec des États allemands (M. Sommerfeld, M. Strobel, E. Lachmann, S. Meder). Au début de chaque article (sauf celui de D. Koppe), une table des matières donne une vue d'ensemble pour tous ceux qui s'intéressent à certains aspects spécifiques.

Constituant un petit livre en soi, l'introduction structurée et très claire des éditeurs de l'ouvrage permet de situer les contributions, y compris pour les lecteurs qui ne sont pas familiers de l'histoire du droit des femmes à l'époque contemporaine. Le livre aborde les mouvements bourgeois pour les droits des femmes, qui ont commencé à s'organiser au milieu du XIX ${ }^{\mathrm{e}}$ siècle. Ceux-ci, à la différence des mouvements socialistes, attribuaient un rôle central à l'amélioration du statut (juridique) de la femme dans le cadre de l'ordre social existant. Les positions au sein des mouvements bourgeois pouvaient varier : il s'agissait de donner la priorité soit au suffrage, soit à des réformes en droit privé, de préférer une politique de transformation graduelle ou de changement radical. On partait du principe que la société était modifiée par le droit, ou, au contraire, que le droit était modelé par la société. Concernant le droit privé, les réclamations portaient par exemple sur l'abolition des obligations misogynes résultant du mariage ou sur l'arrêt de discriminations issues du droit des régimes matrimoniaux. Les organisations nationales - qui travaillaient dans des circonstances socio-juridiques différentes mais développaient toutes des formes d'actions similaires, comme la diffusion d'écrits, l'entretien de relations publiques ainsi que la tenue de réunions régulières - ont été suppléées en 1888 par une organisation internationale, le Conseil international des femmes (CIF). Le CIF influait sur les mouvements nationaux grâce, entre autres, à des rapports nationaux présentés lors de ses congrès, permettant aux actrices de tirer argument à l'échelle de leur propre pays de la situation plus favorable dans d'autres pays. C'est cette "gesellschaftlich[e] Vorbereitungsarbeit» («travail de préparation sociale », p. 91) qui constitue pour S. Meder et C.-E. Mecke la contribution 
décisive des féministes du XIXe siècle à l'amélioration de la condition juridique des femmes au XX $\mathrm{X}^{\mathrm{e}}$ siècle.

Sur cette trame, les thèmes centraux des contributions concernent, pour commencer, les mouvements féministes, en particulier leurs revendications en matière de droit privé, les acteurs et les débats. À l'exception des États-Unis, toutes les « régions » du recueil sont abordées (C.Wallat, R. Kuru, J. Strecker, A. Toulas). Les questions de propriété des femmes mariées occupent en outre une place éminente. La plupart des auteurs ont choisi à ce propos une approche de l'histoire du droit traditionnelle mettant l'accent sur l'incapacité des femmes mariées et sur ses critiques en France ainsi que sur la doctrine de coverture en Common Law, qui a disparu pendant la deuxième moitié du XIX ${ }^{e}$ siècle en vertu des lois et des règles du jurisprudence en Angleterre et dans quelques États fédéraux américains (P. Klees; S. Kitsakis; J. Stender-Vorwachs, $\mathrm{N}$. Theißen ; D. Koppe). Les enfants naturels et leurs droits représentent un autre thème important. Le rôle du bien-être de l'enfant pour justifier les réformes et le peu d'importance accordée aux revendications pour l'amélioration de la situation des enfants naturels au sein des mouvements féministes y constituent les principaux sujets (E. Lachmann, N. Stender, N. Bertram, J. Johannsen). En lien étroit avec le thème des enfants naturels, la question de l'obligation alimentaire, qui pouvait aussi toucher les enfants nés dans le cadre d'un mariage, est également traitée. M. Sommerfeld analyse les dispositions du Code civil français du XIX ${ }^{e}$ siècle tandis que M. Oldenburger détaille les bases légales sur lesquelles des créances alimentaires pouvaient se fonder en Angleterre jusqu'à la fin du XIX ${ }^{\mathrm{e}}$ siècle, comme le bastardy law et le poor law. Les autres contributions concernent la recherche de paternité en France et en Allemagne (E. Lachmann) ainsi qu'aux États-Unis (J. Hamilton-Bick), le droit du divorce en Angleterre et aux États-Unis (S. Leuninger, A. Ihlefeldt), le droit des obligations nées du mariage en France et aux États-Unis (C. Sorge, A. S. Köhn), le modèle de mariage scandinave (S. Meder), le droit de garde en Angleterre (M. Strobel) et le CIF (G. Brandtner, A. Duncker).

$\mathrm{Du}$ point de vue d'une historienne, les points forts de ce recueil sont, avec l'introduction, les articles qui traitent des matières d'histoire du droit avec une approche juridique. Concernant les efforts à intégrer une perspective d'histoire sociale - outre des critiques ponctuelles que l'on pourrait adresser à certains propos individuels -, il aurait été souhaitable de réfléchir brièvement aux sources sur lesquelles se fonde l'analyse (les articles de N. Bertram et de G. Brandtner font ici exception). Les contributions utilisent en effet des matériaux sujets à caution; une véritable réflexion à leur propos pourrait modifier l'analyse. La plupart des sources sont publiées, beaucoup de leurs auteurs sont anonymes, et au moins une édition de sources très problématique, la collection des débats parlementaires anglais « Hansard », est utilisée.

Dans l'ensemble, l'ouvrage présente une vue d'ensemble très intelligible du sujet, entre autres grâce à la clarté de son organisation ainsi qu'à la présence d'un index de personnes et de matières. 
INDEX

Index chronologique : Époque contemporaine

Thèmes : Histoire du droit, Histoire des femmes, Histoire du genre

\section{AUTEURS}

\section{LAILA SCHEUCH}

Max-Planck-Institut für europäische Rechtsgeschichte, Frankfurt am Main 